\title{
Backward, Dumb and Violent Hillbillies? Rural Geographies and Intersectional Studies on Intimate Partner Violence
}

\author{
Linn Sandberg
}

\section{Linköping University Post Print}

\section{Tweet}

N.B.: When citing this work, cite the original article.

Original Publication:

Linn Sandberg, Backward, Dumb and Violent Hillbillies? Rural Geographies and Intersectional Studies on Intimate Partner Violence, 2013, Affilia, (28), 4, 350-365.

http://dx.doi.org/

Copyright: SAGE Publications (UK and US) http://www.uk.sagepub.com/home.nav 


\begin{abstract}
:
Urban and rural geographies should be further included in feminist intersectional research on intimate partner violence. The article reviews existing research on the challenges facing rural victims of IPV. This research makes visible the specific problems rurality imposes on victims of IPV. However, research on rural IPV risks being misused and subsequently reinforcing othering and stereotypes of rurality and rural inhabitants. The article suggests that researchers alternate between intra- and anti- categorical approaches. On the one hand rural victims of IPV should be analysed as a neglected point of intersection, and on the other the diversity of ruralities should be acknowledged.
\end{abstract}

Feminist researchers on violence have made major contributions by highlighting the home as the site of violence, and as anything but a safe place for many women and children. As such, place has played a central role in feminist scholarship on violence. Still, discussions of place are missing in feminist violence research insofar as there is little discussion on the differences between urban and rural localities as the place or context of violence. This is surprising, given the impact of theories on intersectionality within interdisciplinary feminist research. Intersectionality refers to how gender is intrinsically linked to and mutually constituted with other forms of oppression and social locations, for example class, ethnicity, race, sexuality, age, religion and disability (Lykke, 2010; Mehrotra, 2010). Experiences of violence have been particularly important in theorizing on intersectionality. In her seminal article, "Mapping the Margins: Intersectionality, Identity Politics and Violence Against Women of Color” (1991), Kimberlé Crenshaw writes about the interconnectedness of race and gender in women of colour's experiences of violence. Her work has since been carried forward by others, and there is now a considerable bulk of discussion on the need for intersectional approaches to intimate partner violence (IPV), particularly in terms of race and ethnicity but also to some extent with regard to age, disability, class and sexuality (Bograd, 1999; Sokoloff \& Dupont, 2005). However, rural and urban geographies are seldom discussed as relevant to intersectional studies in general or studies of IPV in particular.

In this article I argue that there is a need for feminist research on IPV to take discussions on intersectionality further by including place and rural/urban geographies as social locations, 
which impacts on experiences of violence. As Maria Matsuda (1991, p. 1189) has suggested concerning intersectional analysis, it is important to "ask the other question", to continuously investigate what the blind spots of the current analysis are. Rural/urban geographies could be one such blind spot that requires further interrogation.

Although researchers on rural IPV, mainly from North America and Australia, have for two decades pointed to the adversities facing rural victims of violence (Wendt, 2009), this is still a relatively understudied topic. Pruitt (2008) argues that there is an urban norm in violence research. This norm implies, firstly, that research on IPV perpetrated in urban areas is not discussed in terms of space and place, and secondly, that urban research is assumed to be generalizable to cases outside urban areas as well (Pruitt 2008). As a consequence, the differences that exist between urban and rural regions and the specific conditions and problems rural victims of IPV face are obscured. Existing and future studies on rural IPV are thus of great importance to make visible the experiences of victims and increase the knowledge of how they may or may not exit abusive relationships.

The aim of this article is to discuss place and rural and urban geographies as important to feminist and intersectional studies on violence. But the aim is also to discuss how highlighting rural IPV may contribute to the othering of rurality - reinforcing images and perceptions of rural locations and rural inhabitants as deviant - something that may further marginalize rural victims of IPV. Overall, the objective of the article is to forge a theoretical and conceptual discussion on the relevance of thinking through regional geographies. I use IPV as a specific and significant case within feminist social work here, but my argument could be considered relevant for other fields within social work also.

Mehrotra (2010) argues that feminist intersectional social work in a global context must increasingly incorporate discussions on migration, diaspora and nationality into analyses. In this article I suggest that feminist intersectional social work must also think from the local: the meanings of local geographies and how this impacts on our analyses. Postcolonial scholarship has 
pointed to how geographies and places are intertwined with power asymmetries in a globalized world, not least how Western power-knowledge regimes are imposed on so-called Third World countries (Minh-ha, 1986/1987; Mohanty, 1984; Said, 1993 [1978]; Spivak, 1988) There is considerably less discussion, however, of how urban and rural are not only neutral descriptions of territories but are also linked to power as well as social inclusion and exclusion. Not only are rural regions often socio-economically disadvantaged vis-à-vis urban ones, but the links between urban and centre on the one hand and rural and periphery on the other also influence on what perspectives and voices are heard, I argue. This needs to be further acknowledged, as it impacts on how to understand and research IPV in different rural regions.

I start by outlining and reviewing literature on rural IPV and the strong themes within this research. This is not a systematic review but a way to give readers who are unfamiliar with existing scholarship on rural IPV an idea of the specificities and challenges that confront rural victims of IPV and, consequently, why intersectional analyses of IPV need to consider geography and local place. I continue by considering how discussions on the specificities of place and violence carry an evident risk of othering and of locating violence somewhere else, in places and people imagined to be different from 'us'. In this argument, I draw on some insights from postcolonial and antiracist scholarship and note parallels between this field and rural geography. I conclude that research on rural IPV must alternate between intra- and anti-categorical approaches, that is, between analyses which highlight rural victims as located in a neglected intersection and analyses which deconstruct and challenge urban/rural categories. Existing research on rural IPV has focused primarily on rurality as a material and physical place, but rural place also needs to be considered as a discursive construct.

Before outlining existing research and venturing into a discussion on the risks of reinforcing rural inhabitants as "'internal others"” (Eriksson 2010, p. 96) and how to avoid this, I will clarify some terms and definitions used in the article. I will also locate myself in the text by describing some aspects of my background and academic context. 


\section{Defining IPV, defining rurality, defining my positions}

In terms of the terminology of the article, I use the term intimate partner violence (abbreviated as IPV throughout the article) to refer to violence between individuals who are, or have been, in an intimate relationship, co-habiting and non-cohabiting (Basile \& Black, 2011). Globally, this violence is mainly perpetrated by men against women, and for this reason I sometimes refer to victims as women and perpetrators as men, although IPV can also have women as perpetrators and can occur in same-sex relationships (Basil \& Black, 2011; Rothman, Butchart \& Cerdá, 2003). Along with Basile \& Black (2011, p. 112-113), my definition of IPV does not exclusively involve physical violence but also sexual and emotional/psychological violence, as well as threats of violence and stalking. ${ }^{\mathrm{i}}$

Besides IPV, rural is the term which recurs most frequently in this article. Using this term is not wholly uncomplicated, however. As will become clear in the course of the article I believe there is a need for more location-specific, nuanced discussion on ruralities. This involves acknowledging rurality as "considerably more unstable, diverse, contested and fragmented a phenomenon than commonly perceived" and exploring "the culture of particular rural communities" rather than unitary notions of rural culture (Hogg \& Carrington, 2003, p. 295; Wendt, 2009, p. 177). Accordingly, stable and universalized definitions of rural/rurality are difficult to make. In the literature on rural IPV, a recurring definition of rurality is that of a sparsely populated region with low population density. Although there may be variations in geographical distances and population densities that define rurality in different national contexts, this is the generalized understanding of rurality I use in the article (Pruitt, 2008).

The backdrop of my argument is a Swedish context, which has implications on how rurality and IPV are both understood and conceptualized. Sweden is internationally renowned for its politics and policies on gender equality, and is ranked number one in the 2011 UN Gender inquality index (http://data.un.org/DocumentData.aspx?q=HDI\&id=273). Gender equality has 
emerged as a pervasive discourse in Sweden, and the combating of men's violence against women has become a significant part of the gender equality project as well as a serious social issue (although this happened rather late, in the 1990s) (Hearn et al., 2012; Wendt Höjer, 2002). There is a great discrepancy between the public discourse on violence against women as unacceptable and the continued prevalence of IPV. There is presently no research on the prevalence of IPV in rural Sweden and the experiences of Swedish rural victims of IPV.

The Swedish context of my writing will also be noticeable in my discussions of the risks of reinforcing negative stereotypes of rural place. The rural idyll is an influential discourse in a Nordic context, like in many other contexts (Gunnerud Berg \& Forsberg, 2003). In the Swedish context the rural idyll is strongly connected to nature and the beauty of the Swedish countryside, which are closely tied to the Swedish national self-image. Still, alongside this discourse on rural Sweden as beautiful and peaceful (and by implication non-violent), another discourse on rurality exists: that of rurality as backward and non-progressive. In this discourse rural residents emerge as backward, narrow-minded and traditional (Dahl, 2004; Eriksson, 2010; Stenbacka, 2011). This can be compared to stereotypes of the American hillbilly, representing people of the country as dumb and backward (DeKeseredy \& Schwarz, 2009). My own situatedness is also relevant here, as I grew up in a rural village in Sweden.

My background is in interdisciplinary gender studies, and consequently I move between many different disciplines and fields of knowledge. In this article I use work emerging from rural studies, feminist studies and research on intimate partner violence to ask how insights from these different but sometimes overlapping fields may inform each other.

\section{Central themes in research on rural IPV}

When it comes to the scope of the problem, there are contradictory findings on the prevalence of rural IPV in existing research. Pruitt (2008, p.349f), for example, refers to U.S. research suggesting that "arrests for crimes against family members were four times higher in 
rural locations than in the largest metropolitan cities"(citing Weisheit, Falcone \& Wells, 2006). However, other studies from the United and Canada, both older and more recent, suggest that the rates of IPV are similar in rural and urban locations (e.g. Bachman, 1994; Bachman \& Saltzman, 1995; Brownridge, 2009). Existing research employs both qualitative and quantitative approaches. The work discussed in this article include statistical analyses based on surveys on experiences of rural IPV both among victims themselves and service providers (Bosch \& Bergen, 2006; Brownridge, 2009; Eastman \& Bunch, 2007; Grossman, Hinkley, Kawalski \& Margrave, 2005; Lanier \& Maume, 2009; Logan, Walker, Cole, Ratliff, \& Leukefeld, 2003; Logan, Stevenson, Evans, \& Leukefeld, C. (2004); Peek-Asa et al., 2011; Shannon, Logan, Cole \& Medley, 2006) and studies that use qualitative ethnographic and interview methodologies (Davis, Taylor \& Furniss, 2000; DeKeseredy \& Schwartz, 2009; Shepherd, 2001; Websdale, 1998, Websdale \& Johnson, 1997; Wendt, 2009) I also refer to some significant reviews on rural IPV (Adler 1996; Grama 2000; Pruitt 2008). Existing research is predominantly from the United states, Canada and Australia and little discussion exist on the cultural and contextual variability in cases of rural IPV. ${ }^{\mathrm{ii}}$

\section{Geographical isolation exacerbating overall isolation}

As pointed to earlier, the most common definition of rurality in studies on rural IPV is as sparsely populated regions with low population density. The impact of geographic isolation on rural inhabitants is often posited as a very significant and profound difference between IPV in urban and rural locations (Adler, 1996; Davis, Taylor \& Furniss, 2001; DeKeseredy \& Schwartz, 2009; Grama, 2000; Pruitt, 2008; Websdale, 1998). Isolation, including emotional, social and physical isolation, is a central issue to victims of IPV, not only in rural areas but everywhere. Yet, the geographical isolation that rurality implies tends to exacerbate other forms isolation in cases of IPV. Lanier \& Maume (2009, p. 1322), discuss geographical isolation and social isolation as a "double-edged sword to rural women". In their study, the social support of family and friends proved to be more important to rural women for avoiding being victimized by IPV. Research by 
Brownridge (2009) suggests, however, that rural victims of IPV were less likely to confide in someone in their social networks. Some abusers move to geographically distant locations to further isolate their abused partner from social networks of family, friends and co-workers (Grama, 2000; DeKeseredy \& Schwartz, 2009; Pruitt, 2008). This may contribute to additional emotional isolation and feelings of hopelessness, which further reduce the victim's possibilities to exit the relationship. Distance to neighbours also implies fewer chances that someone will hear/see and intervene, and offers nowhere to escape in an acute situation.

Some victims of IPV in rural areas are vulnerable both from geographical isolation and from the marginalizing effects of, for example, race, ethnicity, disability or immigrant status (Grossman, Hinkley, Kawalski \& Margrave, 2005; Shepherd, 2001). Immigrant women may be particularly vulnerable if they are dependent on their abuser for continued residence (Adler, 1996).

The spatial difference is a marked difference between rural and urban locations, and the geographical distances of rural areas and the isolation this often involves probably comprise the single condition or factor that is generalizable to ruralities of very different contexts. It is probably also, in the words of Grama (2000, p. 177), "the most fundamental difficulty facing the rural battered woman" and which impacts on several other aspects of living in a relationship with violence. The material realities of rural life may worsen geographical isolation. Living in a rural location with no access to a car or public transportation, and where weather conditions can be harsh, may then imply few possibilities to leave one's abuser (Peek-Asa et al., 2011; Shepherd, 2001). Poverty in rural regions could include a lack of infrastructure, such as transport inadequacies and road conditions (Adler, 1996; Grama, 2000, Shepherd; 2001), this leads us on to another important theme within research on IPV and rurality: socio-economic disadvantages of rural areas.

\section{Socio-economic disadvantage and lack of effective services}


Several researchers on rural IPV point to how rural areas may be socio-economically disadvantaged in comparison to urban regions, and how this may effect both the occurrence of IPV and the possible responses. As physical, sexual and emotional abuse is often combined with economic abuse, victims of IPV are often faced with economic problems. Lack of money and jobs in rural areas may then compound with geographical isolation and hinder victims from exiting abusive relationships (Logan, Walker, Cole, Ratliff, \& Leukefeld, 2003; Pruitt, 2008).

The combination of the distances and socio-economic disadvantages of rural areas means less access to effective services and information for rural victims of IPV. Lack of services in rural locations includes the lack of social services, police, courts and shelters, which are often of great significance to victims of IPV. The lack of social services can be seen as particularly detrimental in the light of a study by US researchers Grossman, Hinkley, Kawalski \& Margrave (2005), who suggest that rural victims of domestic abuse were in greater need of services than their urban counterparts. Similarly, in a study by Eastman \& Bunch (2007) on social workers' perceptions of domestic violence in rural localities, the social workers experienced that their clients needed more services. In this study, however, the rural community held limited resources and the social workers often had multiple roles when working with clients.

The socio-economic conditions of rural regions combined with the geographical distances have consequences not least for law enforcement (Brownridge, 2009). US research has indicated that it takes longer for police to arrive, and that it is more likely that they will not show up at all, in cases of domestic violence in rural areas (Websdale \& Johnson, 1997). Rural police, as well as lawyers, local courts, judges and social services, may also have less specialized training in dealing with cases of IPV and are often restrained by a lack of resources (Pruitt, 2008; Grama, 2000; Shepherd, 2001).

Moreover, the lack of health services in rural locations may have major consequences on the health of victims of IPV and may even increase the risk of intimate partner homicide. In an analysis of FBI homicide reports from 1980 and onwards, Gallup-Black (2005) shows that 
intimate partner and family murder increased with rurality. Gallup-Black argues that the inaccessibility to health services may be understood as one explanation for the higher murder rates, as assaults led to death due to a lack of immediate and adequate medical care.

Socio-economic disadvantages of rural regions also impact on voluntary services. Shelters are scarcer in rural regions, and those that do exist are dependent on fewer people to volunteer in a small community, and are more vulnerable due to a lack of funding (Adler, 1996; Grama, 2000). US health researchers Peek-Asa et al. (2011) conducted a cross-sectional survey inventorying and mapping domestic violence intervention programmes (DVIP), and report that rural victims of violence had three times greater distances to the nearest IPV resources and that rural programmes served more counties and had fewer on-site shelter services. They conclude that: "an increased focus on access to preventive services, including DVIP resources, is critically needed" (Peek-Asa et al. 2011, p. 1748).

The socio-economic disadvantages facing rural regions in comparison to urban counterparts are evidently empirical questions that need investigation in different and specific contexts. However, thinking of urban/rural in terms of power asymmetries should also involve discussions of how the rural/urban intersects socio-economic conditions: class and poverty. The extent to which rural regions are economically disadvantaged in relation to urban locations, and how this impacts on prevention and intervention against IPV, are questions that need to be further addressed.

\section{Lack of anonymity in the small community}

Although living in rural communities can involve great isolation, not least for victims of IPV, the rural community may at the same time paradoxically also imply less privacy. Several studies on rural IPV suggest that the social control of the smaller community in a sparsely populated area may lead to less privacy and to having to deal with the stigma of being abused (or an abuser) in a community where everyone knows who you are (Adler 1996; DeKeseredy \& Schwartz, 2009; Grama, 2000; Pruitt, 2008; Websdale, 1998; Wendt, 2009). Wendt (2009) 
discusses how "gossip networks" may hinder women from revealing their situation or seeking help in the community (also Brownridge, 2009). If one reports the violence it could, for example, end up in the only newspaper in the community or on the local radio station, and subsequently be picked up by local people who can easily discern who the involved parties are (Adler, 1996).

When seeking help and formal support in the small community, victims are also more likely to encounter someone they know at the social services, with the police or at the local health station (Adler, 1996; Websdale \& Johnson, 1997; Websdale, 1998). The police may be friends with the abuser, the social worker could be the mother of your children's friends, or the local nurse could be a friend from church. Confidentiality may thus be a greater issue in the rural community, and victims may avoid seeking help if they know they will encounter someone they know in formal, official support services. Research also points to how the small community with its lack of anonymity also makes it difficult to escape the abuser. Safe houses are difficult to keep secret and can be tracked down, which makes the safety of rural women a major issue (Adler, 1996; Davis, Taylor \& Furniss, 2001; Grama, 2000).

That people in a small community know each other is often discussed and understood in positive terms as "social cohesion" and as offering the potential to help each other and prevent crime (DeKeseredy \& Schwartz, 2009). DeKeseredy \& Schwarz (2009, p. 6) assert that US media representations often depict rural people as "nicer to each other than urban residents are". The idea of the cohesion of the rural community is related to the idea of rural areas as more peaceful, idyllic and safe. However, discourses on the idyllic and peaceful rurality where people help each other are at odds with the experiences of rural victims of IPV. DeKeseredy and Schwartz's (2009) study on IPV in rural Appalachia in the US suggests that rural residents are not more likely to help each other in cases of violence in the family. In contrast to other situations of crime in rural areas, for example vandalism, where the fact that people know each other can operate as a social control to be preventive and where the community might mobilize, this does not seem to be the case in relation to IPV (also Websdale, 1998). Rather, as Wendt (2009) points to, discourses on 
the close-knit community and the rural idyll sometimes hindered the women in her Australian study from seeking help and assistance, because they did not want to reveal the abuse to the community. Bosch \& Bergen (2006, p. 312), researching the support networks of rural victims of IPV, point to how social networks that were responsive to other life events were less responsive in cases of IPV, which was experienced as causing "discomfort" or "disapproval". The idea of social cohesion in the small community where people help each other out could thus further alienate and be confusing to victims of IPV when the community did not act upon the violence despite having knowledge of it (Wendt, 2009).

Studies on IPV in rural areas point to how privacy is often valued in rural communities, and how the knowledge of violence was thus something that should be kept in the family (Wendt, 2009). I believe, however, that attitudes and feelings about privacy may vary between rural communities; hence this also needs to be studied empirically in different contexts. Still, as opposed to people in an urban context, rural victims of IPV are generally more geographically isolated while at the same time often less anonymous in the rural community, a complex and paradoxical situation that needs to be considered by researchers.

\section{IPV and the rural community - strengths and weaknesses of an intra-categorical approach}

What is perhaps the greatest strength of existing research, as discussed above, is how it makes visible the experiences of rural victims of violence, as a largely invisible group within research and policy. In her thorough review and discussion of IPV in rural regions, Pruitt (2008) argues that the missing discussion on the conditions of rural IPV and on the relevance of place in research on IPV is a reflection of an urban norm that privileges the urban outlook. Websdale (1998) and DeKeseredy \& Schwartz (2009) argue along the same lines, stating that rural crime is given little attention, which may be a result of a common understanding of rural areas as nonproblematic and peaceful in comparison to the crime rates of urban locations. In this argument, 
the conception of violence as a problem of the city obfuscates the experiences of rural victims of abuse (also Adler, 1996; Grama, 2000; Wendt, 2009). The invisibility of rural victims of violence has consequently been one of the primary motivations for researchers to focus on rural IPV.

None of the studies discussed above on rural IPV explicitly use the word intersectionality. However, they could be understood as examples of "implicit intersectional analyses", which do not engage in "meta-theoretical reflections on "intersectionality" but still focus intersections of gender and rurality (and sometimes also class, ethnicity, race) in studies of IPV (Lykke, 2010, p. 76). Drawing on McCall's (2005) outlining of three different methodological approaches to intersectionality, the above studies could be conceptualised as having an "intra-categorical approach". This approach is often referred to as the position adopted by feminists of colour (Lykke, 2010; Mehrotra, 2010), and retains categories for strategic purposes, to analyse "particular groups at neglected points of intersection" (McCall 2005, p. 1774). This description is applicable to studies of rural IPV, for which the invisibility and neglect of rural victims is a recurring motivation to research these issues (Adler, 1996; Dekeseredy \& Schwartz, 2009; Pruitt, 2008; Websdale, 1998). Similarly to how black feminists have pointed to the need to recognize the interconnectedness of race and gender in women of colour's experiences of violence, it is possible to argue that the experiences of rural victims of abuse must be understood through the interconnectedness of gender and rural geography, which sometimes compound with experiences of poverty.

One of the limitations of existing research on rural IPV is, however, that the meaning of rurality is rarely problematized and that urban/rural are often treated as discrete and pre-existing categories in a rather realist fashion. This is particularly the case in quantitative studies. Although the heterogeneity of rural regions is sometimes acknowledged (e.g. Shannon, Logan, Cole \& Medley, 2006), these acknowledgments warrant no discussion on how we as researchers also shape research categories such as urban or rural. Nor do these acknowledgments lead to discussions on how geographies cannot only be treated as material physical places but as 
discursive constructs imbued with various (unstable) meanings and associations. Next I will therefor argue for the need for intersectional analyses of rural IPV that are not only "intracategorical", highlighting rurality as a blind spot in violence research, but also "anti-categorical". Following McCall (2005) the anti-categorical approach involves the critique and deconstruction of categories, based on an epistemological position whereby categories are linked to normative and oppressive structures. I will suggest that an uncritical use of the category rural in studies of IPV may contribute to the othering of rurality where negative stereotypes of "backward, dumb and violent hillbillies" are reproduced.

\section{Avoiding the othering of rurality - Towards an anti-categorical approach}

In their article on domestic violence and intersections of class, race and gender, Sokoloff $\&$ Dupont (2005) argue that one of the challenges researchers face is to represent marginalized women in ways that do not further marginalize and disadvantage them. This is a worthwhile point to consider in research and policy work on rural victims of IPV as well. In this part of the article, I will argue that singling out rural violence carries risks of feeding into negative and stereotypical discourses on rurality. By drawing parallels to postcolonial and anti-racist scholarship I will discuss how research highlighting IPV in rural regions may contribute to the othering of rurality, turning these regions into inherently problematic and non-progressive geographies. My discussion will concentrate on assertions of "rural patriarchy" and "crisis in the rural gender order" as often-used explanations for violence.

By using the term othering in my discussion, I relate to the seminal work of postcolonial theorist Edvard Said (1993 [1978]) on the Orient. Said argues that the positioning of the Orient as inferior and fundamentally different in Western thought is central to the construction and definition of the West. Processes of othering thereby involve the constitution of the self through the differentiation and repudiation of an imagined Other. Subsequent work has since expanded Said's theorizing to also discuss the divisions within regions and nations (cf. Eriksson, 2010). 
Scholarship on postcolonialism has been preoccupied with geo-politics related to colonialism and how geographical positioning matters to humans' economic and political situation (Landström, 2001). But there is also a small body of work on more local and national geographies and how these relate to power relations. Similarly to how discourses on the Orient function to shape the West as civilized, modern and exalted, the positioning of some regions within a nation as problematic may function to shape national identity (Eriksson, 2008; 2010; Jansson, 2003; 2005 Johnson \& Coleman, 2012). Eriksson (2010), for example, discusses how the region of the rural North emerges as an internal other in Sweden.

In existing literature rural IPV is recurrently discussed and made sense of in relation to specific rural gender relations as well as to a "rural patriarchy". An early influence on discussions on IPV and rural patriarchy was Websdale's (1998) study on rural Kentucky women, where he points to the need to address the specificities of rural patriarchies as contexts in which the violence occurs. Drawing on Walby's theories on public versus private patriarchies, in which rural patriarchies are discussed as private and based on household production, Websdale (1998, p. 48) states:

By rural patriarchy I am referring to that articulation of patriarchy found distinctively in rural areas. Put specifically, the relatively autonomous structures referred to by Walby (the patriarchal household; paid work; the patriarchal state; patriarchal culture; patriarchal sexuality; and male violence) manifest themselves differently in rural areas, although these structures still constitute a readily discernible set of gender power relations.

Several subsequent studies on rural IPV employ Websdale's theories on rural patriarchy, pointing to traditionalism and stereotypical gender relations in rural regions as contexts and explanations for the violence (Brownridge, 2009; DeKeseredy \& Schwartz, 2009; Eastman, Bunch, Williams \& Carawan, 2007; Pruitt, 2008; Sudderth, 2006). DeKeseredy \& Schwartz (2009, p.13), for example, discuss the existence of "a powerful ol' boys network" whereby men in the local rural 
community support and condone the violence of other local men. These networks can also involve local police officers and other officials who are friends with the abuser and therefore do not interfere. DeKeseredy \& Schwartz (2009, p. 11) discuss this in terms of "non-intervention norms" in the rural community researched. The need to research violence towards rural women is thus motivated based on their specific vulnerability to male power in the rural community where everyone may know each other, as discussed earlier.

An interlinked discussion to that of IPV and the rural patriarchy is that of a "crisis in the rural gender order" as a presumed cause of IPV in rural regions (Hogg \& Carrington 2006, p. 181 cited in DeKeseredy \& Schwartz, 2009). In an article on rurality, masculinity and violence, Australian researchers Carrington \& Scott (2008) discuss how rural masculinity has historically been associated with nature, authenticity and brute force, and how the rural man has as such been valorized as a more "real" kind of man. They argue, however, that more recent socio-economic changes have contributed to increasing struggles of rural men, understood as unable to keep up with societal changes, which has contributed to the denigration and marginalization of rural masculinity. DeKeseredy \& Schwartz $(2009$, p.99) take the arguments of Carrington \& Scott further by discussing rural men's violence in relation to a “masculinity crisis/male peer support theory of separation and divorce sexual assault” (also Hogg \& Carrington, 2006). Men's violence towards their intimate partners in rural regions is made sense of here as a consequence of rural social and economic transitions, diminishing the traditional power of rural men. DeKeseredy \& Schwartz (2009, p.101) argue that "a sizeable portion of unemployed rural men who strongly adhere to the ideology if familial patriarchy compensate for their lack of economic power by exerting more control over their wives." Men's violence towards their intimate partners is thus made sense of as a result of economic transition whereby men are losing their former positions and power.

It may well be the case that there were particular patriarchal gender relations in the contexts studied by Websdale (1998) and others, and as a feminist I sympathize with the 
ambitions to analyse the links between gender relations and IPV. Still, thinking from an anticategorical approach, researchers must also critically interrogate the categories we use and how power relations are re-inscribed from our classifications. As McCall (2005, p. 1777) argues: "the methodological consequence" of an anti-categorical approach is "to render suspect both the process of categorization itself and any research that is based on such categorization, because it inevitably leads to demarcation, and demarcation to exclusion, and exclusion to inequality." In this case it is relevant to explore what the consequences may be of the categorization and demarcation of rural patriarchy and particular rural gender relations.

By using categorizations such as rural patriarchies researchers feed into particular discourses on urban and rural regions and geographies. In the Swedish case, for example, researchers have argued that Swedish rurality is largely negatively connoted and posited as something problematic. In a representation analysis of the film The Hunters, Eriksson (2010) underlines that the people of the rural North are represented as being everything the Swedish capital of Stockholm and its urban inhabitants are not: backward, violent, racist, homophobic and sexist. Stockholm and the Swedish urban inhabitants emerge as modern and progressive in contrast to the rural inhabitants. Swedish researchers have, moreover, pointed to how a central part of the popular discourse on Swedish rurality as problematic, non-progressive and backward is in fact the image of the stereotypical gender relations of Swedish rural inhabitants. Rural men particularly are represented as backward and unable to keep up with modern ideals of gender equality (Eriksson, 2010; Stenbacka, 2011). ${ }^{\text {iii }}$ Ethnographic studies by Dahl (2004) and Nordin (2007) suggest that rural women are represented and understood as progressive and modern when moving away from the countryside, whereas rural men are understood as "losers" who are left behind and are unable to form modern gender-equal relationships with women (also Eriksson, 2008).

In a context where rurality is positioned as problematic, backward and non-progressive, such as in the Swedish case, there is an evident risk that research on rural IPV that singles out 
rural geographies as marked by particular patriarchies and traditional gender relations may contribute to the othering of rurality. It is possible to draw parallels here to how the suburb in Swedish discourses is positioned as a problematic place within urbanity, and to how non-white immigrant inhabitants of suburban locations are constructed as more gender-conservative and reliant on patriarchal ideologies than white Swedes (de los Reyes, 2003; Bredström, 2002). Swedish researchers on ethnicity and racism have pointed to how non-white minority populations are "culturalized" and understood as more patriarchal and how, as a result, violence towards women in these communities is understood as a natural consequence of culture (de los Reyes, 2003). The work of Said has contributed to our understanding of how the West has emerged as enlightened, modern and progressive by making the Orient into its non-progressive other. As Jansson (2003) indicates, local rural regions may in a similar fashion become "the internal other", which function to exalt the national identity and urban regions. Research focusing on IPV and rurality could then become yet another way of locating violence somewhere else, this time in the internal other, embodied in rural men and women. From an anti-categorical approach formulating social policy on IPV and rural geographies may not only reinforce negative stereotypes of "violent hillbillies" but also obscure IPV in urban localities since urban inhabitants are understood to be more modern and gender equal, and as a consequence less violent. Thus, generalizing understandings of "patriarchal 'immigrant' or ethnic minority cultures" as well as "rural patriarchies" are not necessarily helpful to rural victims of violence. Violence instead becomes naturalized and understood as an inherent part of the rural or "immigrant"/minority culture.

The parallels to how non-white or other minority populations have been positioned as the violent other also underline that the problems and risks of othering rural inhabitants are not new, and that lessons may be learned from earlier discussions on intersectionality and violence (cf. Bograd, 1999; Crenshaw, 1991; Davis, 2000; Sokoloff \& Dupont, 2005; Yllö, 2005). ${ }^{1}$ Crenshaw (1991, p. 1256) writes about the problems of dealing with violence in non-white communities out 
of fear of contributing to racism, of "reinforcing distorted public perceptions". It is possible to consider how negative discourses on rural inhabitants may similarly hinder rural victims of violence from revealing violence so as not to reinforce these discourses.

By pointing out how research on rural IPV runs the risk of othering rurality I do not wish to dismiss the significance of existing studies on rural IPV. These studies have been of great importance for putting the blind spot of rurality on the map in IPV research. However, from my discussion on the risks of othering rurality I suggest that researchers must simultaneously engage in anti-categorical analyses, which deconstruct and challenge unitary understandings of rural/urban. Ruralities should be discussed not only as physical places but just as much as "imagined communities" that are socially and culturally constituted (Carrington \& Scott 2008, p. 642 citing Anderson, 1991; Wendt 2009) While researchers such as DeKeseredy \& Schwartz (2009) have pointed to how romanticized positive discourses of peaceful and idyllic ruralities have obfuscated IPV in rural communities, these researchers have failed to acknowledge the more negative discourses existing on rurality, where IPV is understood as part and parcel of backward rural culture. Intersectional feminist research that highlights the relevance of local place and urban/rural geographies for studies of IPV must continuously clarify how urban and rural categories are associated with power/knowledge, where urban often come to represent the modern and progressive and rural the traditional and backward.

\section{Bringing geography into the intersectionality: concluding discussion}

The aims of this article have been, firstly, to point to the need to include rural and urban geographies in feminist intersectional studies of IPV and, secondly, to discuss the risks of othering rurality when highlighting rural IPV. From a review and discussion of existing work on rural IPV I have suggested that this work could be categorised as intersectional analyses that are “intra-categorical”, which highlights positions which are made invisible in current research. Studies on IPV have, on the one hand, predominantly focused on urban locations, and rural research has, on the other hand, not been preoccupied with IPV, which leaves rural victims of 
IPV unheard and unseen. Still I am critical towards how the majority of research on rural IPV does not problematize meanings of rurality. Rural geographies are primarily discussed as material and physical places, and little discussion exists on how rural place also shapes within specific discourses. Drawing on the Swedish example I argue that when rural geographies are negatively represented as backward research that uncritically employs notions such as "rural patriarchy" may contribute to the othering of rurality. For this reason I propose that research on rural IPV must move between intra-categorical and anti-categorical approaches, where the latter deconstructs rural and urban as categories and locate local geographies within discourses of power and knowledge. My proposition resonates the argument of Mehrotra (2010), who suggest that feminist social work scholarship must engage with a continuum of intersectionality theorizing from a wide range of epistemological positions. Below I will make some brief remarks on what I consider to be the implications of my discussion to future research in feminist social work and to feminist social workers in the field.

Shifting between intra and anti-categorical approaches requires a great deal of epistemological flexibility from researchers. Rurality and urbanity may, on the one hand, be used as categories for strategic uses, to point to structural differences between different geographies, for example in terms of inequalities related to class, poverty and lower educational attainment in some rural regions and how this links to IPV. At the same time it is necessary to also embrace a position where the categorization of rural and urban is problematic and leads to demarcation. In short, intersectional analyses on rural and urban geographies must simultaneously treat rural and urban as both "real" and "not real".

While I understand the intra-categorical approach to reflect on the omissions of current research, in this case the invisibility of local geographies, I understand the anti-categorical approach to reflect on the omissions of one's own research practices. Similarly to how studies on women and femininity can contribute to the naturalization and invisibility of men and masculinities, and how gay and lesbian studies can contribute to the invisibility of 
heterosexuality, a focus on the rural can contribute to the invisibility and reinforcement of an invisible urban norm, where urbanity is never discussed in terms of place. When focusing on IPV in rural areas, we as feminist social work researchers must constantly ask: in what ways do we contribute to images of this place as deviant and to what extent to we (re)render urban place continuously invisible, unproblematic and taken for granted (cf. Stenbacka 2011)?

Furthermore, to bring local geographies into intersectional analyses in feminist social work requires us to think a bit differently. To date, intersectional studies on domestic violence or IPV have focused primarily on the intersections of race, ethnicity and gender and to some extent on those of class, age, sexuality and disability (Sokoloff \& Dupont, 2005; Ekström 2013 f.c.) These are all linked to acknowledged power asymmetries such as sexism, racism, classism, ageism and ableism and homophobia. In comparison to race, class and gender, for example, it may be less evident how urban/rural geographies are also linked to power and to societal inclusion and exclusion. The socio-economic disadvantage of many rural regions, as discussed in the review, is one potential example of marginalization. Differences between urbanity and rurality are not only a matter of a distribution of resources, however, but are also linked to the privileges of definition that come with being situated as either at the centre or at the periphery. The omission of the voices of rural victims of IPV but also of rural social problems more widely, as pointed out by Pruitt $(2007 ; 2008)$ among others, could be understood as a reflection of this peripheral position, outside the centre of knowledge production in feminist social work and elsewhere. Still urban and rural geographies cannot be conceptualized as axis of oppression per se, and for this reason I suggest that intersectional studies in feminist social work think of rurality as imposing particular kinds of vulnerability to individuals. This parallels the discussion of Brownridge (2009, p. 12ff) who proposes that researchers on IPV should focus on "vulnerable populations" in contrast to the more traditional intersectional approach of looking at “oppression/inequality" since vulnerable groups such as rural women are not necessarily oppressed from rurality. Rurality imposes specific vulnerabilities that cannot be reduced to class, 
gender or other, I argue, and by bringing regional geographies into intersectional analyses we as scholars are thus more capable of understanding experiences of violence as well as other social issues.

Evidently a great deal of the discussion in this paper has been about epistemology when studying rural IPV, and this leads on also to questions of methodology. I do not suggest any one particular methodological approach as the most feasible to study rural IPV. However, one study which I find to successfully explore rural IPV is Wendt's (2009) ethnographic study of an Australian rural community, where she explores how the local rural culture influences women's experiences of, and men's perpetration of, domestic violence. The strength of this research is how it interrogates how the rural place is made sense of among rural inhabitants themselves, and what the local constructions of violence are. Overall this study is less concerned with what rural culture is and more concerned with "exploring the culture of particular rural communities" and how IPV is enacted and responded to in different ways (Wendt 2009, p. 177). From my perspective this kind of ethnographic study does not start with any fixed notion of rurality and IPV in rural culture but studies local and volatile constructions of both IPV and rurality, and may as such allow for both intra- and anti-categorical approaches.

The discussions of this article should not be seen as relevant only to researchers in social work, but also of potential use to feminist social workers in the field. Intersectionality is important to feminist social work practice since the lives of clients we encounter are indeed shaped at the crossroads of various intersections. To improve practice on IPV knowledge on how not only gender and gender relations but also geographical location impacts on IPV is thus of great importance to feminist social workers. This knowledge could help to better identify the particular vulnerabilities of victims of abuse who are living in diverse rural locations. More concretely, if rural IPV involves a paradoxical situation of geographical isolation while victims at the same time are less anonymous in the small community, feminist social workers could aim to find specific strategies to confront this situation. This could, for 
example, involve raising awareness in the rural community about IPV in order to make it possible for victims to reveal abuse without feelings of shame and stigma and of letting one's community down. Strategies may also involve identifying ways in which informal social networks could be mobilised to confront violence and help victims of abuse. If many people in a small community know each other what are the positive and supportive social relations that may be mobilised to stop IPV? If rural victims of abuse are in need of more help and support from formal services due to multiple vulnerabilities while resources are scarce, as researchers have argued, this is a serious issue that cannot be confronted by individual social workers. Still, lack of resources may call for further discussions among social workers on possible collaborations and coordination among existing services (cf. Wendt 2010). How could, for example, local health resources, police and social services be more coordinated to identify and challenge IPV in the community?

Feminist social workers' attempts to find effective strategies to work with IPV in rural communities must, moreover, be accompanied with social policies that highlight rural IPV as a potential blind-spot. These social policies should reflect nuanced discussions on geography and IPV, pointing to both similarities and differences between rural and urban IPV. Social policy must, similarly to research, be formulated in ways which acknowledge power relations between urban and rural geographies and how a singling out of rural IPV may contribute to negative discourses about rurality.

I understand intersectionality as a theoretical, methodological and practical tool that values a "'bottom-up' approach", starting in the experiences and lives of the most marginalized (Association for Women's Rights in Development, 2004, p. 5). By bringing in regional geographies and discussions on the differences between rural and urban geographies, feminist social work could better understand the marginalization of subjects and how place may intersect with class, ethnicity, race, gender, sexuality, age and many other social locations. This may in 
turn contribute to increasing visibility and support for social workers working victims of IPV or other vulnerable clients in rural areas.

\section{Acknowledgments:}

This article was funded with the aid of the Bank of Sweden Tercentenary Foundation (Riksbankens jubileumsfond). The author would like to thank the participants at the Higher Seminar, Department of Social work, Linköping University for comments on an earlier draft of this article. A special thanks to Professor Margareta Hydén and Associate Professor Lucas Gottzén, Linköping University, who have taken the time to give detailed feedback on the article.

\section{References}

Adler C. (1996). Unheard and unseen: Rural women and domestic violence. Journal of NurseMidwifery, 41, 463-467.

Anderson, B. (1991). Imagined Communities: Reflections on the Emergence of Nationalism. New York: Verso. (Cited in Carrington \& Scott, 2008)

Association for Women's Rights in Development. (2004). Intersectionality: A Tool for Gender and Economic Justice. (retrieved from: http://www.awid.org/eng/content/view/full/41854/\%28language\%29/eng-GB , 2012-1010)

Bachman, R. (1994). Violence Against Women: A National Crime Victimization Survey Report, Bureau of Justice Statistics, U.S. Department of Justice, Washington, DC.

Bachman, R., and Saltzman, L. (1995). Violence Against Women: Estimates From the Redesigned Survey (NCJ-154348), Bureau of Justice Statistics, U.S. Department of Justice, Washington, DC.

Basile K. C. \& Black M. (2011). Intimate partner violence against women, In: Renzetti et al. (eds.) Sourcebook on violence against women. 2. ed. Los Angeles: Sage.

Bograd, M. (1999). Strengthening domestic violence theories: Intersections of Race, Class, Sexual orientation and Gender, Journal of Marital and Family therapy, 25, 275-289.

Bosch, K. \& Bergen, B. (2006). The Influence of Supportive and Nonsupportive Persons in 
Helping Rural Women in Abusive Partner Relationships Become Free from Abuse. Journal of Family Violence, 21, 311-320.

Bredström, A. (2002). Maskulinitet och kamp om nationella arenor: reflektioner kring bilden av 'invandrarkillar' i svensk media, In: De los Reyes P., Mulinari D. \& Molina I. Maktens (o)lika förklädnader: kön, klass \& etnicitet i det postkoloniala Sverige, Stockholm: Atlas, 182-206.

Brownridge, D.A. (2009). Violence against women: vulnerable populations. New York: Routledge

Carrington, K., \& Scott, J. (2008). Masculinity, rurality and violence. British Journal of Criminology, 48, 641-666.

Crenshaw, K.W. (1991). Mapping the Margins: Intersectionality, Identity Politics, and Violence against Women of Color. Stanford Law Review, 43, 1241-1299.

Dahl, U. (2004) Progressive Women, Traditional Men: The Politics of 'Knowledge' and Gendered Stories of 'Development' in the Northern Periphery of the EU, Diss., Santa Cruz, University of California.

Davis, A. (2000). The color of violence against women, Key note address of the color of violence conference at University of California at Santa Cruz, Retrieved at May 25, 2012, from: http://colorlines.com/archives/2000/10/the_color_of_violence_against_women.html.

Davis, K., Taylor, B. \& Furniss, D. (2001). Narrative accounts of tracking the rural domestic violence

survivors journey: a feminist approach. Health Care for Women International, 22, 333347.

DeKeseredy, W.S., Schwartz, M.D. (2009). Dangerous Exits. Escaping Abusive Relationships in Rural America. New Brunswick, NJ: Rutgers University Press.

de Los Reyes, P. (2003). Patriarkala enklaver eller Ingemansland? Våld hot och kontroll mot unga kvinnor i Sverige. Integrationsverkets skriftserie IV.

Eastman, B.J. \& Bunch, S.G. (2007). Providing services to survivors of domestic violence: a comparison of rural and urban service provider perceptions. Journal of Interpersonal Violence. 22, 465-473.

Eastman, B.J., Bunch, S.G., Williams, A.H. \& Carawan, L.W. (2007). Exploring the Perceptions of Domestic Violence Service Providers in Rural Localities. Violence Against Women, 13, 700-716. 
Ekström, V. (2013) Samhällets stöd till våldsutsatta kvinnor: en intersektionell analys av hur det offentliga trycket behandlar kön, klass och etnicitet. Retfaerd, 35, 51-68

Eriksson, M. (2008). (Re)producing a "peripheral" region - northern Sweden in the news, Geografiska Annaler: Series B, Human Geography 90, 369-388.

Eriksson, M. (2010). "People in Stockholm are smarter than countryside folks"' - Reproducing urban and rural imaginaries in film and life”. Journal of Rural Studies, 26, 95-104.

Gallup-Black, A. (2005). Twenty Years of Rural and Urban Trends in Family and Intimate Partner Homicide: Does Place Matter? Homicide Studies, 9, 149-173.

Grama, J.I. (2000). Women Forgotten: Difficulties Faced by Rural Victims of Domestic Violence. American Journal of Family Law, 14, 173-189.

Grossman, S., Hinkley, S., Kawalski, A. \& Margrave, C. (2005). Rural Versus Urban Victims of Violence: The Interplay of Race and Region. Journal of Family Violence, 20, 71-81.

Gunnerud Berg, N. \& Forsberg, G. (2003). Rural geography and feminist geography: discourses on rurality and gender in Britain and Scandinavia. In: Simonsen, K., Öhman, J. (eds.), Voices from the North: New Trends in Nordic Human Geography. Ashgate, Aldershot.

Hearn, J., Nordberg M., Andersson, K., Balkmar, D., Gottzén, L., Klinth, R., Pringle, K., Sandberg L, (2012). Hegemonic Masculinity and Beyond: 40 Years of Research in Sweden. Men and masculinities, 15, 31-55.

Hogg, R., Carrington, K. (2003). Violence, Spatiality and Other Rurals. Australian \& New Zealand Journal of Criminology, 36, 293-319.

Hogg, R. \& Carrington, K. (2006) Policing the rural crisis, Sydney Aus Federation Press. Jansson, D.R. (2003). Internal orientalism in America: W.J. Cash's The Mind of the South and the spatial construction of American national identity, Political Geography, 22, 293- 316. Jansson, D.R. (2005). “A geography of racism”: internal orientalism and the construction of American national identity in the film Mississippi Burning, National Identities, 7, 265285 .

Johnson, C. \& Coleman, A. (2012). The Internal Other: Exploring the Dialectical Relationship Between Regional Exclusion and the Construction of National Identity. Annals of the Association of American Geographers, 102, 863-880.

Lanier, C. \& Maume, M.O. (2009). Intimate Partner Violence and Social Isolation Across the 
Rural/Urban Divide. Violence Against Women, 15, 1311-1330.

Landström, C. (2001). Postkoloniala texter. Stockholm: Federativ.

Logan, TK., Walker, R., Cole, J., Ratliff, S. \& Leukefeld, C. (2003). Qualitative Differences Among Rural and Urban Intimate Violence Victimization Experiences and Consequences: A Pilot Study. Journal of Family Violence, 18, 83-92.

Logan, T.K,., Stevenson, E., Evans, L., \& Leukefeld, C. (2004). Rural and urban women's perceptions of barriers to health, mental health, and criminal justice services: Implications for victim services. Violence and Victims, 19, 37-62.

Lykke, N. (2010). Feminist studies: A Guide to Intersectional Theory, Methodology and Writing. New York: Routledge.

Matsuda, M. (1991). Beside My Sister, Facing the Enemy: Legal Theory out of Coalition, Stanford Law Review, 43, 1183-1192.

McCall, L. (2005). The Complexity of Intersectionality. Signs: Journal of Women in Culture and Society, 30, 1771-1800.

Mehrotra, G. (2010). Toward a Continuum of Intersectionality Theorizing for Feminist Social Work Scholarship, Affilia: Journal of Women and Social Work, 25, 417-430.

Minh-Ha, T.T. (1986/1987). She, The Inappropriate/d Other, Discourse, 8

Mohanty, C. (1984). Under Western Eyes: Feminist Scholarship and Colonial Discourse. Boundary 2, 12/13, 333-358.

Nordin, L. (2007). Man ska ju vara två: män och kärlekslängtan i norrländsk glesbygd. Diss. Stockholm: Stockholms universitet, 2007.

Peek-Asa C., Wallis A., Harland K., Beyer K., Dickey P., Saftlas A. (2011). Rural Disparity in Domestic Violence Prevalence and Access to Resources. Journal of Women's Health, 20, 1743-1749.

Pruitt, L.R. (2007). Toward a Feminist Theory of the Rural. Utah Law Review, 2, 421-488.

Pruitt, L.R. (2008). Place matters: Domestic Violence and Rural Difference. Wisconsin Journal of Law, Gender \& Society, 23(2), 347-414.

Rothman, E., Butchart, A. \& Cerdá, M. (2003). Intervening with Perpetrators of Intimate Partner Violence: A Global Perspective. World Health Organisation, 2003. 
Said, E.W. (1993 [1978]). Orientalism. Stockholm: Ordfront.

Shannon, L., Logan,T.K., Cole, J., Medley, K. (2006). Help-Seeking and Coping Strategies for Intimate Partner Violence in Rural and Urban Women, Violence and Victims, 21, 167181.

Shepherd, J. (2001). Where Do You Go When It's 40 Below? Domestic Violence Among Rural Alaska Native Women, Affilia, 16, 488-510.

Sokoloff, N.J. \& Dupont, I. (2005). Domestic Violence at the Intersections of Race, Class, and Gender: Challenges and Contributions to Understanding Violence Against Marginalized Women in Diverse Communities. Violence Against Women, 11, 38-64.

Spivak, G.C. (1988). Can the Subaltern Speak? In: Nelson C., Grossberg L. Marxism and the Interpretation of Culture Urbana, IL: University of Illinois Press, 271-313.

Stenbacka, S. (2011). Othering the rural: About the construction of rural masculinities and the unspoken urban hegemonic ideal in Swedish media. Journal of Rural Studies, 27, 235244.

Sudderth, L. (2006). An uneasy alliance: law enforcement and domestic violence victim advocates in a rural area. Feminist Criminology, 1, 329-353.

UN Data, Human Development Indices: A statistical update 2011, Gender Inequality Index [http://data.un.org/DocumentData.aspx?q=HDI\&id=273\#15] Accessed 2013-03-04.]

Websdale, N. 1998). Rural Women Battering and the Justice System - An Ethnography. Sage Publications, Thousand Oaks, CA.

Websdale, N., Johnson, B. (1997). The Policing of Domestic Violence in Rural and Urban Areas: The Voices of Battered Women in Kentucky. Policing \& Society. 297, 297-317.

Weisheit, R., Falcone, D.N \& Wells L.E. (2006). Crime and Policing in Rural and Small-Town America (3rd ed.), Long Grove: Waveland Press (cited in Pruitt, 2008)

Wendt Höjer, M. (2002). Rädslans politik: våld och sexualitet $i$ den svenska demokratin. Diss. Stockholm : Univ., 2002.

Wendt, S. (2009). Constructions of local culture and impacts on domestic violence in an Australian rural community. Journal of Rural Studies, 25, 175-184.

Wendt S. (2010). Building and sustaining local co-ordination: an Australian rural community responds to domestic and family violence. British Journal of Social Work, 40, 44-62 
Yllö, K.A. (2005). Through a Feminist Lens: Gender, Diversity and Violence - Extending the

Feminist Framework, In: Loseke, D.R. et al. (ed.), Current Controversies on Family Violence. 2. ed. Thousand Oaks, CA: Sage Publications.

\section{Footnotes}

\footnotetext{
${ }^{\mathrm{i}}$ I use the term intimate partner violence rather than domestic violence since I find it to be more inclusive, also involving violence outside marriage and cohabitation; but also since the term IPV is more in line with established Swedish terminology on domestic violence (compare to the Swedish term "våld i nära relationer").

ii Articles on IPV in which rural or rurality are indicated as keywords or as part of the title do not always explicitly discuss the potential differences or implications of rurality on cases of IPV. Rather, rural is often used as a mere description of the location of the research. The research literature discussed in this article, however, more explicitly deals with potential differences in the rates and severity of IPV in rural and urban locations as well as contextual specificities in terms of risk and protection factors for rural inhabitants.

iii This is the representation, for example, in the film The Hunters, but also in various Swedish TV productions, as discussed by Stenbacka (2011). In her study of three TV series on rural Sweden, she finds three different repertoires: rural as help-seeking and backward; rural as marked by gender inequality; and rural as deviant. Stenbacka (2011) and Eriksson (2010) both emphasize that these representations have consequences on the constructions of rurality in a wider sense and also impact on the political agenda.
} 